\title{
UN SISTEMA DE ACUMULACIÓN DE COSTOS PARA LAS EMPRESAS DEL SECTOR AGROINDUSTRIAL FRIGORÍFICO*
}

\author{
ELI SAUL ROJAS RUIZ"; OLGA ROSA MOLINA DE PAREDES $S^{* * *}$ \& GALIA BEATRIZ CHACÓN PARRA \\ UNIVERSIDAD DE LOS ANDES (VENEZUELA)
}

Recibido/Received/Recebido: 06/04/2015 - Aceptado/ Accepted / Aprovado: 10/02/2016

\begin{abstract}
Resumen
El propósito de esta investigación es presentar los lineamientos de un sistema de acumulación de costos para las empresas del sector agroindustrial frigorífico, que les permita el costeo de sus productos y, a su vez, la adopción de decisiones más informadas y acertadas. Las técnicas de recolección de datos utilizadas fueron la observación directa, la observación documental y las entrevistas no estructuradas aplicadas a los jefes de producción y contabilidad de los Frigoríficos Industriales del Estado Mérida (Venezuela). Los resultados evidencian que los registros contables tradicionales poco satisfacen las exigencias informativas que plantea el mercado dinámico del sector agroindustrial frigorífico. Se concluye, que el sistema de acumulación de costos por procesos con la aplicación de métodos de asignación de costos conjuntos basados en los precios de mercado es el apropiado para las empresas de este tipo de industria.

Palabras clave: Sistemas de acumulación de costos; Producción conjunta; Métodos de asignación de costos conjuntos; Mataderos y frigoríficos industriales.
\end{abstract}

\footnotetext{
Este trabajo presenta los resultados de una investigación empírica realizada como tesis de grado para la Maestría en Ciencias Contables del maestrando Eli Saul Rojas Ruiz, coautor de este artículo. Se inserta en la línea de investigación denominada contabilidad y gestión de costos, adscrita al Grupo de Investigación en Finanzas, Auditoría, Ambiente, Contabilidad, Epistemología y Ética (GIFACE) del Postgrado en Ciencias Contables de la Facultad de Ciencias Económicas y Sociales, Universidad de Los Andes (ULA), Mérida - Venezuela.

** Licenciado en Contaduría Pública, Especialista en Tributos y Magister Scientiae en Ciencias Contables del Postgrado en Ciencias Contables, de la ULA. Profesor Asociado adscrito al Departamento de Contabilidad y Finanzas de la Facultad de Ciencias Económicas y Sociales de la ULA y Coordinador del Servicio Comunitario de dicha facultad. Presidente del Instituto de Desarrollo Profesional (IDEPRO) del Colegio de Contadores Públicos del Estado Mérida - Venezuela. Miembro activo del Grupo de Investigación en Finanzas, Auditoría, Ambiente, Contabilidad, Epistemología y Ética (GIFACE). Dirección postal: Universidad de Los Andes, Facultad de Ciencias Económicas y Sociales, Departamento de Contabilidad y Finanzas, Avenida Las Américas, La Liria, Edificio F, Nivel 2, Mérida,Venezuela, C.P. 5101. Teléfono: 0274-2401043 / 0274-2401165. Correo electrónico: elisaul@ula.ve

*** Licenciada en Contaduría Pública y Magister Scientiae en Administración del Centro de Investigaciones y Desarrollo Empresarial (CIDE), de la ULA. Doctora en Formación, Empleo y Desarrollo Regional, de la Universidad de la Laguna, Tenerife - España. Profesora Titular adscrita al Departamento de Contabilidad y Finanzas de la Facultad de Ciencias Económicas y Sociales de la ULA. Miembro activo del Grupo de Investigación sobre Agricultura, Gerencia y Ambiente (GISAGA) y del Grupo de Investigación de las Organizaciones (GIO). Correo electrónico: molinap@ula.ve

${ }_{* * * *}^{*}$ Licenciada en Administración y Magister Scientiae en Ciencias Contables del Postgrado en Ciencias Contables, de la ULA. Profesora Titular y Jefe de la Cátedra de Contabilidad de Costos adscrita al Departamento de Contabilidad y Finanzas de la Facultad de Ciencias Económicas y Sociales de la ULA. Miembro activo de la Comisión Curricular de la Licenciatura en Contaduría Pública y del Grupo de Investigación en Finanzas, Auditoría, Ambiente, Contabilidad, Epistemología y Ética (GIFACE). Correo electrónico: gbchacon@ula.ve
} 


\title{
A COST ACCUMULATION SYSTEM FOR THE REFRIGERATION AGRIBUSINESS SECTOR COMPANIES
}

\begin{abstract}
The purpose of this research is to present the outlines of a cost accumulation system for the refrigeration agribusinesses sector, allowing them proper costing of their products and, in turn, get more informed and accurate decision-making. The data collection techniques used were direct observation, documentary observation and not structured interviews applied to accounting and production managers from the industrial refrigeration sector from the state of Merida (Venezuela). The results show that traditional accounting records little satisfy the information requirements posed by the refrigeration agribusiness sector dynamic market. It is concluded that the per process costs accumulation system with the joint costs allocation method application based on market prices is appropriate for companies in this field of industry.

Keywords: Cost accumulation systems; Joint production; Joint costs allocation methods; Slaughterhouses and industrial refrigerators.

\section{UM SISTEMA DE ACUMULAÇÃO DE CUSTOS PARA AS EMPRESAS DO SETOR AGROINDUSTRIAL FRIGORÍFICO}

\section{Resumo}

O propósito desta pesquisa é o de apresentar os lineamentos de um sistema de acumulação de custos para as empresas do setor agroindustrial frigorífico, que lhes permita o custeio de seus produtos e a adoção de decisões mais informadas e acertadas. As técnicas de coleta de dados utilizadas foram a observação direta, a observação documentária e as entrevistas não estruturadas aplicadas aos chefes de produção e contabilidade dos Frigoríficos Industriais do Estado Mérida (Venezuela). Os resultados evidenciam que os registros contábeis tradicionais pouco satisfazem as exigências informativas propostas pelo dinâmico mercado do setor agroindustrial frigorífico. Conclui-se que o sistema de acumulação de custos por processos com o aplicativo de métodos de atribuição de custos conjuntos baseados nos preços de mercado é o apropriado para as empresas deste tipo de indústria.

Palavras chave: Sistemas de acumulação de custos; Produção conjunta; Métodos de atribuição de custos conjuntos; Matadouros e frigoríficos industriais.

Rojas, E., Molina, O. \& Chacón, G. (2016). Un sistema de acumulación de costos para las empresas del sector agroindustrial frigorífico. En: Revista de la Facultad de Ciencias Económica: Investigación y Reflexión. rev.fac.cienc.econ, XXIV (2), DOI: http://dx.doi.org/10.18359/rfce.2215

JEL: D20, D24, M41. 


\section{Introducción}

Los modernos métodos de producción y las características particulares de los mercados han originado cambios fundamentales en las formas de la actividad organizacional. La diversidad y, en especial, los gustos y necesidades de los consumidores han dado un carácter cada vez más transitorio a los productos, por ende a sus procesos productivos y los sistemas contables.

La contabilidad de costos ha posibilitado, a través de los años, que las organizaciones tomen decisiones adecuadas y oportunas sobre temas relacionados con los costos de producir y vender. No obstante, para las empresas que normalmente tramitan miles de documentos, la acumulación y clasificación de los costos de forma rutinaria se convierte en una laboriosa tarea que consume gran cantidad de recursos humanos (Morillo, 2002) y, por supuesto, también financieros.

En consecuencia, las empresas no conocen la estructura de costos de sus procesos, ni la situación financiera de cada uno de sus productos, sólo conocen su situación financiera general y agregada (Sierra, 2002). Esto les ocasiona un serio problema por cuanto les dificulta conocer cuál es la verdadera utilidad que cada uno de los productos aporta a las ganancias de la empresa. Igualmente, no conocen su punto de equilibrio, situación en la que no se producen pérdidas pero tampoco beneficios.

La contabilidad general o financiera suministra información relacionada con el flujo externo de operaciones que convergen en la empresa, tales como: compra de materia prima, pago del personal y a proveedores, venta de productos, cobro a clientes, entre otras. En tanto que la contabilidad de costos acumula, define, clasifica, mide, registra, reporta y analiza el flujo interno de valores económicos (costos directos $e$ indirectos asociados con la producción, comercialización y distribución de bienes y servicios así como los relacionados con la administración y financiación), con el objeto de suministrar la información necesaria para facilitar y mejorar el proceso de toma de decisiones en todos los niveles de la jerarquía empresarial (Chacón, 2007).
Por otra parte, el sistema de acumulación de costos comprende los procedimientos, métodos y demás registros que permiten suministrar información acerca del costo de producción de un artículo o de la prestación de un servicio. De hecho, para Lavolpe (2005) son procedimientos técnicos, administrativos y contables que pueden ser utilizados por cualquier tipo de empresa para determinar el costo de las diversas fases de sus operaciones - sectores, departamentos, actividades, procesos - con fines de información contable (valoración de inventarios, costo de ventas, generación de resultados), control de gestión (diagnóstico, planificación, evaluación) y base para la toma de decisiones (cálculo de la contribución marginal y aplicación de la relación costovolumen-utilidad en la fijación de precios, eliminación de una línea de producto o la tercerización de actividades).

En suma comprenden una herramienta fundamental de las organizaciones que pretende explicar, desde diversas aristas y para satisfacer distintos propósitos de información, el comportamiento de los costos de sus operaciones. Conforme a Meigs \& Meigs (1994, p. 3), “(...) un sistema contable comprende los métodos, procedimientos y recursos utilizados por una entidad para seguir la huella de las actividades financieras y resumirlas en forma útil para quienes toman las decisiones". De ahí que las empresas requieran y creen sistemas contables que incluyan procedimientos de costeo que les permitan la presentación de sus estados financieros, además de servir estos sistemas de soporte para la planificación, control y toma de decisiones.

Para el sector agroindustrial frigorífico, los conceptos de proceso productivo son más complejos que en otros sectores industriales por la diversidad de productos conjuntos, subproductos y desechos que se derivan del sacrificio del ganado en pie destinado al consumo humano, lo cual exige un sistema contable que responda a las inquietudes presentadas por la gerencia de las empresas dedicadas a esta actividad, sobre su verdadera situación económica y financiera. Los temas relacionados con los costos de producir y vender son puntos de primer orden en las reuniones de junta directiva de las empresas del sector cárnico, donde con frecuencia predomina 
la necesidad de conocer la estructura de costos y el desempeño de cada línea de negocio, así como también los resultados obtenidos en cada periodo.

En la actualidad la industria cárnica venezolana se encuentra en serias dificultades y, por eso, la información de costos es vital para los mataderos y frigoríficos industriales nacionales. Segovia y Jerez (2008) señalan que los principales nudos críticos a los que se enfrenta este sector agroindustrial son:

- La anarquía por falta de zonificación, proliferación indiscriminada de salas de matanza y aumento de la capacidad ociosa en casi el $40 \%$ del sector, aunada a la obsolescencia gerencial de la mayor parte de los mataderos $\mathrm{y} / \mathrm{o}$ frigoríficos industriales, producen altos costos a lo largo de la cadena de transformación que se traducen en pérdida de la rentabilidad. Por tanto, en el sector agroindustrial frigorífico nacional prosperan el desaprovechamiento de las instalaciones, el deterioro de la eficiencia en la explotación de subproductos, el descontrol higiénico-sanitario, el deterioro e indefinición de la calidad de la canal, la participación de un gran número de intermediarios que no añaden valor al producto pero que tienen grandes márgenes de ganancias, el incremento de los costos de comercialización y los problemas ambientales, entre otros.

- Los entes públicos responsables de estas instalaciones no vigilan debidamente su buen funcionamiento, ya sea, por el desconocimiento o la práctica común de ignorar las normas jurídicas correspondientes. El gobierno nacional se ha enfocado básicamente en el producto final, limitando la oferta y ejerciendo controles a través de un estricto régimen de regulación de precios.

- La inexistencia de un proceso de supervisión y de auditorías así como la falta de actualización profesional por parte de la Unidad Técnica Nacional de la Carne del Ministerio de Producción y Comercio ha producido una elevada discrecionalidad en el clasificador de animales en canal y una gran diversidad de criterios diferenciados entre clasificadores para distinguir los rasgo de calidad de la carne. En consecuencia, la formación del precio en el sector es poco transparente y perjudica la confianza entre eslabones y la competitividad de la cadena, especialmente en el establecimiento de precios por parte del estado sin la participación del sector privado.

- El doble sometimiento del clasificador, por una parte, a organismos del estado como el Ministerio del Poder Popular para la Agricultura y Tierras o el Instituto Nacional de Salud Agrícola Integral, y por la otra, a la propia empresa beneficiadora de reses que le proporciona bonos al funcionario oficial, influye en su función de árbitro imparcial y deviene en corrupción por sobornos o conflictos de intereses entre productores, matarifes, clasificadores intermediarios o dueños de carnicerías durante la clasificación de la canal.

Lo que sucede en el mercado cárnico en Venezuela es causa de su estado de atraso por la falta de información y transparencia (Piñate, 2010). Asimismo, de manera análoga a la situación destacada por Sabata (2010) para las explotaciones porcinas en el contexto español, en el sector agroindustrial frigorífico venezolano la mayoría de las empresas pequeñas y medianas no solicitan asesorías especializadas para el análisis de costos, sólo lo hacen las grandes empresas ya sea obteniendo esta información a través de profesionales externos o internos $y$ aunque el objetivo principal no es precisamente obtener un análisis económico de la empresa sino el análisis técnico de la producción, cabe mencionar que estos dos análisis no son incompatibles, antes bien son complementarios, por lo que es primordial que toda explotación agroindustrial tenga información relativa tanto a la gestión técnica como la gestión económica.

En una industria tan dinámica como la cárnica, donde las alternativas de canalización y dirección de la producción deben estudiarse diariamente debido a las fluctuaciones de sus costos - como por ejemplo el alimento, la mano de obra, los medicamentos o cualquier otro insumo relacionado con las operaciones normales de funcionamiento de las empresas de este sector -, además de ocupar la carne un producto de la cesta básica venezolana, se hace impres- 
cindible la definición de un sistema de acumulación de costos, ausente en los mataderos y frigoríicos industriales, que refleje su ciclo operativo completo; desde que las reses son dispuestas a la matanza hasta obtener los múltiples cortes y subproductos. Sin embargo, la investigación empírica relativa al costeo del proceso de beneficio de reses en las distintas zonas ganaderas del país es escasa.

Por tal motivo, el objetivo de esta investigación es presentar los lineamientos de un sistema de acumulación costos para las empresas del sector agroindustrial frigorífico del estado Mérida, que les permita el costeo adecuado de sus productos y, a su vez, la adopción de decisiones más informadas y acertadas. Un sistema de acumulación de costos apropiado posibilitará reunir, organizar y comunicar información financiera y no financiera acerca del proceso productivo y la determinación de los costos en los mataderos y frigoríficos industriales de esta localidad, como base para pronosticar las consecuencias económicas de las decisiones gerenciales que se adoptan en su seno y promover mejoras en su productividad.

El artículo se ha estructurado contemplando, en primer lugar, la naturaleza de los sistemas de acumulación de costos; en segundo lugar, la producción conjunta y los métodos para la asignación de los costos conjuntos; en tercer lugar, la metodología utilizada; en cuarto lugar, se presentan los resultados; y en quinto lugar, se exponen algunas conclusiones $y$ consideraciones finales.

\section{Naturaleza de los sistemas de acumu- lación de costos}

La contabilidad de costos ofrece los métodos pertinentes para la determinación de los costos de producción, los cuales se configuran como un traje a medida para satisfacer las necesidades de información sobre los procesos que ocurren en el interior de las empresas y, a su vez, secundar a la administración en la elaboración, ejecución y control de los planes estratégicos de negocio. De ahí, el desacierto de las empresas de no poseer un sistema adecuado de acumulación de costos.
La formulación empírica de costos, entendida como la falta de fundamentación científica y metodológica en el cálculo de los costos, con el propósito de responder a las urgencias de información aunque puede ser sustento temporal para la adopción de decisiones gerenciales, no permite disponer de los medios idóneos para determinar lógica y efectivamente los resultados, incluso se puede fracasar ante la falta de una base o un sistema de acumulación de costos, especialmente cuando la complejidad de las operaciones industriales hace necesaria la prudente medición de los costos incurridos (Oropeza, 2005). En efecto, como señala Sierra (2002) sin un sistema de información apropiado las empresas se ven en serias dificultades para:

- Tomar decisiones en cuanto a qué hacer con el o los productos que están produciendo pérdidas, o cuyas ganancias están por debajo de las aspiraciones de la empresa, así como la de mantener el producto que está produciendo pérdidas o sacarlo del mercado.

- Estudiar las razones por las cuales los productos están en esa situación y tomar decisiones para resolver el problema. Por tanto, se debe saber si el problema se debe a una situación de mercadeo del producto o a un problema en alguna parte de su estructura de costos.

- Evaluar la estructura de costos de los productos versus el establecimiento de control de precios de los mismos.

Los sistemas de información, como apunta López (1999), aunque refiriéndose particularmente al sistema de información de gestión, desempeñan un papel preponderante en el incremento de la capacidad empresarial para encarar el cambio ambiental y en el aumento de su viabilidad, producto del logro de una mayor correspondencia entre los entornos turbulentos en que se sitúan las decisiones y los mapas cognitivos, que posibilitan la interpretación de las diversos estados de esos entornos así como la formulación y puesta en marcha de estrategias destinadas a mejorar la efectividad, productividad y, en definitiva, la competitividad de la empresa y de sus personas. Pero las empresas no se valen de un sistema único de información para dirigir el curso de sus acciones, cuentan con múltiples sistemas de 
información para la consecución de sus objetivos, dentro de los cuales la contabilidad es el sistema de información formal por excelencia (Chacón, 2010).

De acuerdo a Oropeza (2005), la contabilidad de costos cumplen dos finalidades principales dentro de una organización: una de tipo contable, que consiste en servir de base para la valuación de los inventarios y, por ende, la determinación y presentación de los resultados en un periodo; y otra aplicable a la alta gerencia, que permite la oportuna evaluación de alternativas de actuación empresarial, posibilitando la toma de decisiones acertadas para el manejo de los negocios. Esto requiere de un cúmulo de procedimientos y métodos apropiados, que configurando diversos sistemas de costeo según las características de los procesos productivos reflejen claramente las operaciones y los costos de la empresa, cualquier sea su tipo, manufacturas o de servicios, base fundamental para la toma de decisiones.

Los sistemas de contabilidad de costos son, un mecanismo formal para reunir, organizar y comunicar información sobre las actividades de una empresa. Un buen sistema de costeo ayuda a una empresa a alcanzar sus metas y objetivos. El propósito de un sistema de contabilidad de costos es medir el costo de desarrollar, producir, adquirir, vender y distribuir productos o servicios particulares. Por eso se pueden definir como el conjunto de procedimientos, técnicas, registros e informes estructurados sobre la base de la teoría de la partida doble y otros principios técnicos, que tienen por objeto la determinación de los costos unitarios de producción y el control de las operaciones fabriles efectuadas en una empresa (Ortega, 1997).

Constituyen la base de acumulación de los costos de producción, es decir, significa el medio o método utilizado para acumular los costos que se van adherir a los productos o servicios. La acumulación y clasificación de datos rutinarios del costo del producto son tareas muy importantes que además demandan mucho tiempo, pues la acumulación de costos implica la recolección organizada de datos de costos mediante un conjunto de procedimientos o sistemas (Polimeni et al., 1994). La literatura especializada atendiendo a la naturaleza del proceso de produc- ción reconoce, aunque representan enfoques extremos, dos sistemas básicos de acumulación de costos: el sistema de costos por órdenes específicas y sistema de costos por procesos.

El sistema de acumulación de costos por órdenes, también conocido con los nombres de costos por producción, por lotes de trabajo o por pedidos de los clientes, es propio de aquellas empresas cuyos costos se pueden identificar con el producto, en cada orden de trabajo en particular, a medida que se van realizando las diferentes operaciones de producción en esa orden específica (Gómez, 2005). Es apropiado para aquellas empresas que fabrican sus productos mediante el ensamblaje de varias partes hasta obtener un producto acabado, en el cual los diferentes productos pueden identificarse fácilmente por unidades o por lotes individuales, como las industrias tipográficas, las artes gráficas en general, la industria del calzado, de muebles, de juguetes, fundiciones, astilleros, los talleres de mecánica, las sastrerías, entre otras que elaboran productos a la orden y especificaciones de los clientes.

La unidad de costeo generalmente es un producto único o lote de productos similares, pero no idénticos, cuya fabricación se inicia mediante una orden de producción, los costos son acumulados por separado para cada orden y la obtención de costos unitarios es cuestión de una simple división de los costos totales de cada orden entre el número de unidades producidas a través de esa orden (Hargadon \& Múnera, 2004). De ahí que sus objetivos según Gómez (2005) sean:

- Calcular el costo de producción de cada producto que se elabora, mediante el registro adecuado de los tres elementos del costo - materiales directos, mano de obra directa y costos indirectos de fabricación - en las hojas de costos por trabajo.

- Mantener en forma adecuada el conocimiento lógico del proceso productivo de cada producto. Así, es posible seguir en todo momento el proceso de fabricación.

- Mantener un control de la producción, con miras a la reducción de los costos en la elaboración de nuevos lotes de trabajo. 
El sistema de acumulación de costos por procesos, tiene como particularidad especial el que los costos de los productos se calculan por periodos, durante los cuales la materia prima sufre un proceso de transformación continua, bien sea en procesos repetitivos o no para una producción relativamente homogénea, en la que no es posible identificar los elementos del costo de cada unidad terminada (Oropeza, 2005). Este tipo de sistema es particularmente utilizado en empresas con procesos de producción masiva y continua de artículos similares, como las industrias de textiles, de procesos químicos, plásticos, cementos, acero, azúcar, petróleo, vidrio, minería, entre otras; en las cuales la producción se acumula periódicamente en los departamentos de producción o en centros de costos.

La unidad de costeo en este sistema la constituye un proceso de producción, por tanto, los costos se acumulan para cada proceso durante un tiempo determinado y el costo unitario del producto acabado está formado por la sumatoria los costos unitarios de los procesos por donde haya pasado, los cuales se determinan dividiendo el costo de cada proceso por el total de unidades obtenidas en el periodo respectivo (Hargadon \& Múnera, 2004). Lo que significa que el costo unitario de producción es un costo promedio, acumulativo y periódico, que crece según las unidades avanzan por los diversos procesos en los que se divide el sistema productivo de la empresa.

La tendencia moderna de acumulación de costos, como consecuencia de una tecnología más avanzada, es hacia la aplicación del sistema de costeo por proceso con datos estándares lo cual facilita en mayor medida la planeación y el control de la producción. El costeo estándar también simplifica la determinación de costos de los productos de las empresas que operan por procesos, produciendo ahorros útiles en los cálculos al proporcionar pronósticos de lo que deben ser los costos unitarios para las categorías de los materiales directos, las unidades recibidas del departamento anterior y los costos de conversión (Hansen \& Mowen, 2007). Siguiendo a Gómez (2005), los principales objetivos del sistema de costos por procesos son:
- Calcular, en un tiempo determinado, los costos de producción de un proceso particular que se puede realizar en un solo departamento o en varios.

- Ayudar a la empresa en el control de su producción, a través de los informes que sobre cada centro de costo debe rendir. Con estos informes, la gerencia puede mantener un adecuado control de la producción.

Estos sistemas de costeo pueden basarse en datos, ya sean, históricos o predeterminados. En el primer caso, se considera que los elementos del costo son reales, aunque tal aseveración no sea en esencia cierta por cuanto el tercer elemento, los costos indirectos de fabricación, sólo se pueden calcular para un periodo corto mediante la utilización de una tasa predeterminada de costos indirectos. En el segundo caso, se tienen en cuenta datos predeterminados que posteriormente se confrontarán, al final de un periodo, con los datos reales, con miras a mantener un adecuado control de la producción durante el proceso mismo de elaboración de los productos.

Los beneficios de un sistema de acumulación de costos se centran en la confiabilidad y oportunidad de la información de costos para tomar decisiones oportunas y acertadas. Uno de los objetivos de la gerencia es tomar decisiones adecuadas, de ellas dependerá la permanencia de la empresa en el mercado. No se puede improvisar, con un sistema de acumulación de costos que no refleje los verdaderos costos de producción para administrar la empresa y mucho menos para establecer precios de venta. La rigurosidad del diseño de los sistemas de costeo y la formalidad con la que se implanten permitirá controles apropiados para cada uno de los elementos del costo, logrando de esta forma una optimización en los costos de producción y realizar propuestas de precios.

\section{Producción conjunta y métodos de asignación de costos conjuntos}

El proceso de manufactura de algunas empresas permite obtener diversos productos finales que son producidos a partir de una misma materia prima y/o conjunto de operaciones, estos procesos se 
conocen como producción conjunta. Los productos de estos procesos pueden hacerse identificables en el punto de separación, pese a que algunos, puedan requerir un mayor procesamiento posterior. Para Hansen \& Mowen (2007) los productos conjuntos están tan intrincados que una vez que se decide producir, las decisiones gerenciales tienen poco efecto sobre el resultado final, al menos hasta el punto de separación.

Los orígenes de los costos conjuntos son de diferente naturaleza, aun cuando, reflejan una situación común, como lo es la diversidad de productos derivados de los mismos costos de producción (Sinisterra, 2006). Las empresas que se encuentran en esta situación se enfrentan al problema de decidir cómo se van a dividir los costos conjuntos entre los productos resultantes. Con la ayuda de la tecnología moderna, muchos de los productos que se manufacturaban por separado, ahora se fabrican a partir de la misma materia prima y haciendo uso del mismo proceso de manufactura, como también de la misma tecnología y mano de obra.

Entre las industrias que poseen producción conjunta están las de refinación de petróleo, lácteos, productos farmacéuticos, productos químicos y procesadoras de alimentos, como las empacadoras de carnes que obtienen diferentes cortes de carne, pieles y residuos de animales beneficiados. Cada una de estas empresas hace uso de las mismas entradas de materias primas a sus procesos, para conseguir diversas salidas en proporciones más o menos fijas $y$ los costos incurridos en este proceso son comunes para todos los productos obtenidos. Sin embargo, debe tenerse presente que estos productos se relacionan de tal modo que el aumento en la producción de uno aumenta la producción del otro o los otros, aunque no necesariamente en la misma proporción, de hecho, hasta el punto de separación no se puede elaborar más de uno sin producir más de los demás (Hansen \& Mowen, 2007).

En esta situación, los únicos costos que pueden acumularse con exactitud son los costos totales (materias primas o materiales directos, mano de obra directa y costos indirectos de fabricación) del proceso que genera los productos simultáneos (Hargadon \&
Múnera, 2004). Lo que significa que los costos conjuntos se componen de todos los costos en que se incurren hasta el punto de separación y para asignarlos a los productos individuales se requieren de ciertos procedimientos que se aplican según como los productos conjuntos sean clasificados. Pero cabe acotar que los costos conjuntos difieren de los costos comunes, si bien todos ellos son costos indirectos porque tales costos no pueden ser rastreados directamente hacia los productos finales que benefician (Hansen \& Mowen, 2007).

Los costos conjuntos se generan en los procesos productivos donde se obtienen varios productos a la vez que no pueden ser fabricados de modo independiente, por tanto, son indivisibles y no identificables con los productos individuales; mientras que, los costos comunes se incurren para elaborar productos de modo simultáneo que además podrían fabricarse por separado, pero a diferencia de los costos conjuntos, son divisibles y pueden asociarse con cada uno de los productos elaborados (Lang, 1981; Polimeni et al., 1994; Gayle, 1999; Torres, 2002). La imposibilidad de vincular los costos conjuntos con los diversos productos ocasiona que las distribuciones de estos costos sean arbitrarias (Backer et al., 1983; Hansen \& Mowen, 2007), en otras palabras, que no exista una forma teóricamente correcta y bien aceptada de determinar qué parte del costo conjunto le corresponde a cada producto (Hansen \& Mowen, 2007).

Más allá del punto de separación si algunos productos requieren de procesos ulteriores para darles condición de acabados y disponibles para la venta, pueden causarse costos adicionales de procesamiento o costos separables. Estos costos comprenden los costos de materias primas o materiales directos, mano de obra directa y costos indirectos de fabricación invertidos en los procesos adicionales de los productos identificables, por ello el costo de cada producto debe incluir los costos conjuntos asignados y los costos separables (Polimeni et al., 1994; Gayle, 1999).

Horngren et al. (2012) clasifican los productos resultantes de un proceso de producción conjunta en dos categorías: productos con un valor de venta po- 
sitivo, en la cual agrupa a los productos principales, productos conjuntos o coproductos y subproductos que poseen un mercado activo; y productos con un valor de venta cero, en la que se ubican los desechos, desperdicios y/o residuos sin valor comercial. En la actualidad es casi imposible encontrar productos sin un valor de mercado, ya que, los avances tecnológicos y el reciente interés por los problemas ambientales ocasionados por el uso irracional de los factores de producción, han hecho que muchos productos y desperdicios - como el aserrín que no tenía un valor de venta o ciertos productos fuera de uso que no poseían un mercado activo - sean comercializados o, incluso, utilizados como materia prima en la elaboración de otros productos. No obstante, el centro de interés de este trabajo son los productos con un valor de venta positivo, los cuales se hace necesario definir y diferenciarlos entre sí.

Los productos principales derivados de un proceso conjunto de producción se denominan productos conjuntos o coproductos y, como indica García (2001), presentan las siguientes características:

- Utilizan insumos compartidos, es decir, se generan de manera simultánea a partir de la misma materia prima, mano de obra y costos indirectos.

- Tienen una fase en el proceso de producción en que se separan en productos identificables y se pueden vender como tales o ser sometidos a procesos adicionales.

- Tienen un procesamiento común simultáneo, es decir, ningún producto se puede producir en forma individual sin que al mismo tiempo surjan los demás productos.

- Los productos conjuntos son el objeto fundamental de las operaciones fabriles.

- Todos se consideran de igual importancia, ya sea por las necesidades que cubren o por su valor comercial, en relación con la producción total.

En este sentido, referirse a productos principales sería lo mismo que hablar de productos conjuntos. Pero Horngren et al. (2012) establecen una diferencia sutil por la variedad de ellos que se obtienen, es decir, cuando un proceso de producción conjunta genera un producto con un alto valor de ventas en comparación con los valores de ventas de los otros productos, ese producto se adjetiva principal, en contraste, cuando un proceso de producción conjunta origina dos o más productos con altos valores de venta en comparación con los valores de venta de los restantes productos, esos productos se designan conjuntos o coproductos.

Por otra parte, se pueden obtener productos secundarios que son denominados subproductos. Torres (2002) los define como aquellos productos que surgen como consecuencia del proceso de producción conjunta, sin ser una parte deseada del proceso, debido a que presenta una capacidad significativamente inferior de generar ingresos en comparación con la de un producto conjunto. Estos productos tienen un valor de mercado inferior $y$, usualmente, se producen en menores cantidades que los productos principales $y / o$ productos conjuntos.

Los subproductos son el resultado incidental de fabricar los productos principales, que se derivan de la limpieza de los productos principales y la preparación de las materias primas o materiales directos previo a su empleo en la producción de los productos principales, o se forman de los desechos sobrantes del procesamiento de los productos principales, los cuales pueden venderse en el mismo estado en que surgen junto a los productos conjuntos en el punto de separación o someterse a un procesamiento adicional antes de ser vendidos (Polimeni et al., 1994). En ocasiones, los subproductos se distinguen de los desechos, en que tienen un valor de venta relativamente más elevado y contribuyen en mayor proporción a las utilidades de la empresa, induciendo un interés directo en su producción (Hargadon \& Múnera, 2004).

Representan entonces residuos de valor, que con frecuencia requieren un tratamiento particular (Lang, 1981). La forma de proceder con respecto a los subproductos es menos compleja que la de los productos conjuntos, pues por definición el valor de los subproductos no es relevante en relación con el valor total de los productos elaborados, sin embargo, esto no siempre es así porque según sean las diversas industrias varía mucho su importancia, 
siendo en algunas empresas el valor de ventas de los productos secundarios tan pequeño que se consideran sinónimos de desperdicios, pero en otras el valor de ventas es tan significativo que se duda si el producto es un subproducto o un producto conjunto (Neuner \& Deakin, 1982).

Las distinciones entre productos principales, productos conjuntos y subproductos no son tan claras en la realidad (Horngren et al., 2012) y pueden cambiar como consecuencia de las innovaciones tecnológicas en los procesos y productos. Las relaciones entre productos conjuntos y subproductos tampoco son permanentes como sucede con los productos dentro de cada categoría, antes bien, varían cuando la importancia relativa de los productos individuales cambia, de ahí que deban reclasificarse y ajustarse los procedimientos de costeo (Hansen \& Mowen, 2007). El tiempo al igual que la ubicación transforman la percepción del subproducto, por eso suele ser la conveniencia la que determina si un producto múltiple se categoriza y trata como producto conjunto o subproducto (Neuner \& Deakin, 1982).

Esto se debe a que tal diferenciación especulativa es sólo una mera distinción semántica, que permite reconocer el procedimiento contable a seguir para valorarlos y preparar los reportes financieros externos $e$ internos que satisfagan las demandas informativas de la empresa. En la práctica, pese a que el criterio de las ventas relativas es el que comúnmente se utiliza para identificarlos no es definitivo, la clasificación de un producto como conjunto o subproducto depende en gran medida de los objetivos y políticas de la gerencia (Backer et al., 1983).

La asignación de los costos conjuntos a los coproductos puede realizarse aplicando cualquiera de los siguientes enfoques (Horngren et al., 2012): bajo el enfoque de mercado, aplica costos conjuntos usando datos como los precios, incluyendo el método del valor de ventas en el punto de separación, el método del valor neto de realización (VNR) y el método del porcentaje constante de la utilidad bruta del VNR; y bajo el enfoque de la producción física, aplica los costos conjuntos usando medidas como el peso, la cantidad, el volumen o las unidades físicas de los productos conjuntos.
En lo que respecta a los subproductos, por su naturaleza de secundarios y poco importantes, en la mayoría de los casos no se les asigna costos conjuntos, simplemente se deduce el ingreso neto que de ellos se puede conseguir de los costos de producción de los productos principales, ya sea, que se reconozcan los subproductos en el momento en que se producen, o bien, en el momento en que se venden. El ingreso neto de los subproductos se calcula restándole a los ingresos del subproducto producido o del subproducto vendido, según sea el caso, los costos separables y los gastos operativos que se le atribuyan. Sin embargo, será el mercado quien defina en el tiempo la imputación o no de costos conjuntos a los subproductos de acuerdo a la importancia que tengan.

Debido a que el tipo de industria que se acomete, el sector agroindustrial frigorífico, considera que todos sus productos son importantes y contribuyen a los beneficios empresariales en función de sus valores relativos de ventas y las cantidades producidas, el estudio contempla únicamente dos de los métodos de asignación de costos conjuntos: el método de las unidades físicas y el método del valor de ventas en el punto de separación. La realidad de los frigoríficos y mataderos industriales es que la totalidad de sus coproductos y subproductos poseen un valor de mercado, hasta los desperdicios que pueden ser utilizados como materia prima para la producción de alimentos agroindustriales. Por consiguiente, conviene que todos los productos cárnicos aquí elaborados reciban costos conjuntos y se denominen indistintamente productos conjuntos y/o subproductos.

El método de asignación con base en las unidades físicas producidas distribuye los costos conjuntos a los coproductos considerando la cantidad de producción total que se obtiene, la cual se puede expresar en barriles, pies cúbicos, toneladas o cualquier otra medida física apropiada (García, 2001). En caso de que la base de medición varíe de producto a producto, debe encontrarse un factor de conversión para uniformar los resultados que se obtengan, lo cual significa que la unidad de medición debe ser la misma para todos los productos conjuntos. Los costos conjuntos se asignan a cada producto conjunto en proporción a la participación que cada uno de ellos 
tiene en la producción total. Para obtener el costo unitario de esta producción, se debe determinar una razón de prorrateo basada en el total de las unidades producidas por todos los productos.

Para Torres (2002), este método presenta algunas desventajas, la principal es, la igualdad de costos unitarios en el punto de separación, lo que no tiene relación directa con la capacidad de los productos conjuntos de generar ingresos y puede ocasionar una asignación excesiva con relación al valor de mercado. En ocasiones, el coproducto menos numeroso es el más caro o tiene un valor de venta mucho mayor que el otro coproducto. Tomar decisiones de negocio con base en costos uniformes como los presenta este método puede promover acciones equivocadas.

El método de asignación con base en el valor de ventas en el punto de separación, según García (2001), aplica los costos conjuntos mediante los precios de venta del mercado de los productos conjuntos en el punto de separación y se desarrolla de la manera siguiente:

- Se obtiene el total de los costos conjuntos.

- Se determina el valor total de ventas para todos los coproductos en el punto de separación.

- Se divide el importe total de los costos conjuntos entre el valor total de ventas para determinar un factor de costo total por cada peso de ventas.

- El factor se multiplica por el valor de venta de cada coproducto para llegar así a la asignación de los costos conjuntos para cada coproducto.

Torres (2002), señala que, según este método se calcula la capacidad de cada coproducto para generar ingresos y en base a ello se asigna el costo conjunto. Los costos asignados de acuerdo a este método son diferentes entre sí, lo cual soluciona parte de la problemática ocasionada por el método anteriormente explicado. Sin embargo, este método no deja de ser injusto, pues ocasiona que los márgenes de contribución de los productos conjuntos sean iguales en todos los casos. De esta forma se cargan más costo conjuntos a los productos conjuntos que poseen más capacidad generadora de ingreso y, de alguna manera, se podría subsidiar a otros.

\section{Metodología}

La investigación se desarrolla como una investigación de campo, esto es, un estudio empírico no experimental. Balestrini (2002) señala que la investigación no experimental se ubica en las investigaciones exploratorias, descriptivas y proyectos factibles, donde se observan los hechos estudiados tal como se manifiestan en su estado natural, y en ese sentido, no se manipulan de manera intencional las variables.

Esta investigación obtiene y procesa datos tomados de fuentes vivas y directas en su contexto natural. En Venezuela, el sector frigorífico formal está conformado por 44 frigoríficos y mataderos industriales que representan una cifra cercana al $80 \%$ de la oferta de carne beneficiada en el país y sobre el cual se mantiene un estricto control y supervisión por parte de las autoridades competentes, en los aspectos relativos a la clasificación de la carne y las condiciones higiénicas sanitarias; mientras que, el 20\% restante de la oferta es cubierta por la producción del sector informal, a través de más de 250 salas de matanza y botalones (Asofrigo, 2010). Del sector formal, se escogieron dos frigoríficos industriales para el estudio empírico.

Los frigoríficos industriales se seleccionan por su accesibilidad, ubicación geográfica cercana a los investigadores y actitud positiva para el suministro de los datos requeridos. Estos frigoríficos son: el Frigorífico Industrial Río Chama, C.A. y el Frigorífico Industrial los Andes, C.A.; ambos localizados en la ciudad de El Vigía, Municipio Alberto Adriani del Estado Mérida.

Las técnicas e instrumentos de recolección de datos utilizados fueron la observación directa, la entrevista no estructurada y la observación documental. Las guías de entrevistas se validaron mediante el juicio de expertos (un experto en contabilidad de costos, un experto en metodología y un experto en lengua y literatura), quienes basándose en su capacidad de discernimiento emitieron criterios respecto a cada una de las preguntas, así como también, observaciones referidas a la presentación de las mismas, llevando a la realización de algunos ajustes que con- 
llevaron a que reuniera los requisitos de validez de contenido. Luego, se aplicaron a los jefes de producción y jefes de contabilidad de los dos frigoríficos industriales seleccionados.

El análisis de los datos consistió en realizar una serie de operaciones a fin de sintetizar los datos recolectados. En este caso, se procedió a organizar la información mediante la presentación de cada una de las preguntas, tomando en cuenta las opciones señaladas por cada uno de los entrevistados, para luego obtener los resultados dados a conocer mediante cuadros resúmenes, cada uno con su correspondiente interpretación cualitativa. En esta investigación las técnicas de análisis, interpretación y presentación utilizadas son: la técnica de observación documental, la técnica de presentación resumida del texto y la técnica del análisis crítico.

\section{Resultados}

Los frigoríficos estudiados valiéndose del ganado en pie como materia prima y agregando un pro- cedimiento industrial altamente tecnificado, obtienen productos terminados destinados al consumo humano y otros productos destinados a la industria agroindustrial. Básicamente, atienden dos líneas de producción:

La línea de beneficio o matanza de reses, para ser comercializadas como carne en canal al mercado nacional, comprende las siguientes etapas (Ilustración 1 ):

Etapa I. Corrales y aturdimiento: Comienza con la recepción de las reses, las cuales después de verificada su legalidad se incorporan a los corrales para darles un baño que las refresque y limpie la piel. Las reses guardan un reposo mínimo de seis horas antes del sacrificio para relajar su sistema nervioso y tener una carne de mejor calidad. Una vez cumplido el reposo se realiza el sacrificio, para el cual se utiliza la pistola de aturdimiento en la cabeza que insensibiliza instantáneamente al animal y se pasa al área de matanza.

Ilustración 1. El proceso productivo de matanza en el sector agroindustrial frigorífico

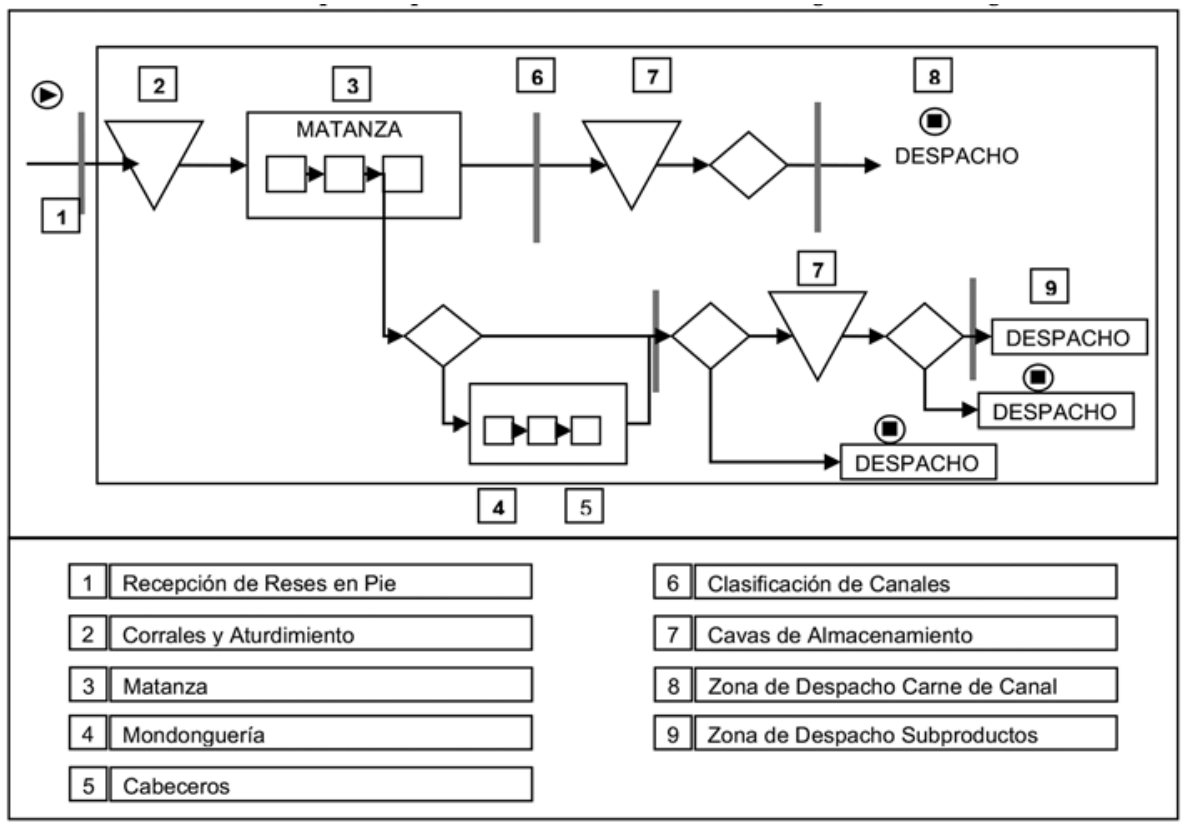

Fuente: Elaboración propia. 
Etapa II. Matanza: Introduce el puñal de succión y se estimula eléctricamente al animal para que el sistema circulatorio bombee sangre al exterior, obteniéndose el primer subproducto, la sangre. Luego, se cortan los cuernos, patas, orejas y, en el caso de las hembras, se extrae la ubre. Sigue el desuelle donde se separa el cuero de la carne y comprende tres sub-etapas: apertura de la piel con cuchillos, desuelle inicial con cuchillos neumáticos y desuelle mecánico total. Desviscerada la res pasa a las secciones de división de la canal, limpieza y acabado. Por último, las canales son clasificadas según criterios de calidad, edad, sexo, madurez, desarrollo muscular y grasas en: AA (óptimo macho), AM (machos), AH (hembras óptimas), B (machos y hembras estándar), $\mathrm{C}$ (vacas y toros) y $\mathrm{D}$ (reses tipo industria).

Etapa III. Mondonguería: Procesa las vísceras blancas y rojas con operaciones de corte, limpieza y blanqueo para obtener subproductos como la panza y el librillo. Las vísceras rojas se comercializan en una sola unidad de medida, llamada traste, compuesta por el corazón, riñones, pulmón, patas, panza, hígado y bofe.

Etapa IV. Cabeceros: La cabeza de la res es aprovechada separando la carne de la cara del animal denominada carnita. Igualmente, se obtienen otros subproductos como los ojos, la lengua, los sesos, etc.

Etapa V. Almacenamiento: Los productos finales de la matanza para su conservación se almacenan en las cavas, con los niveles de temperatura y enfriamiento adecuados.

La línea de desposte, que agrega valor a la carne en canal y la trasforma en productos más detallados y porcionados (Ilustración 2).

Este tipo de industrialización pretende sustituir la forma tradicional de comercialización de la carne y se compone de las siguientes etapas:

Etapa I. Recepción de carne en canal: Recibe la carne en canal con no más de cuatro días de beneficio y a una temperatura promedio de dos grados centígrados, aquí se dividen las canales en paletas y solomos.

Etapa II. Deshuese de la canal: Las paletas y solomos se someten a un proceso de deshuese manual, mediante el cual se obtiene cortes de primera, segunda y tercera, resultando otros subproductos como la grasa y el hueso.

Ilustración 2. El proceso productivo de desposte en el sector agroindustrial frigorífico

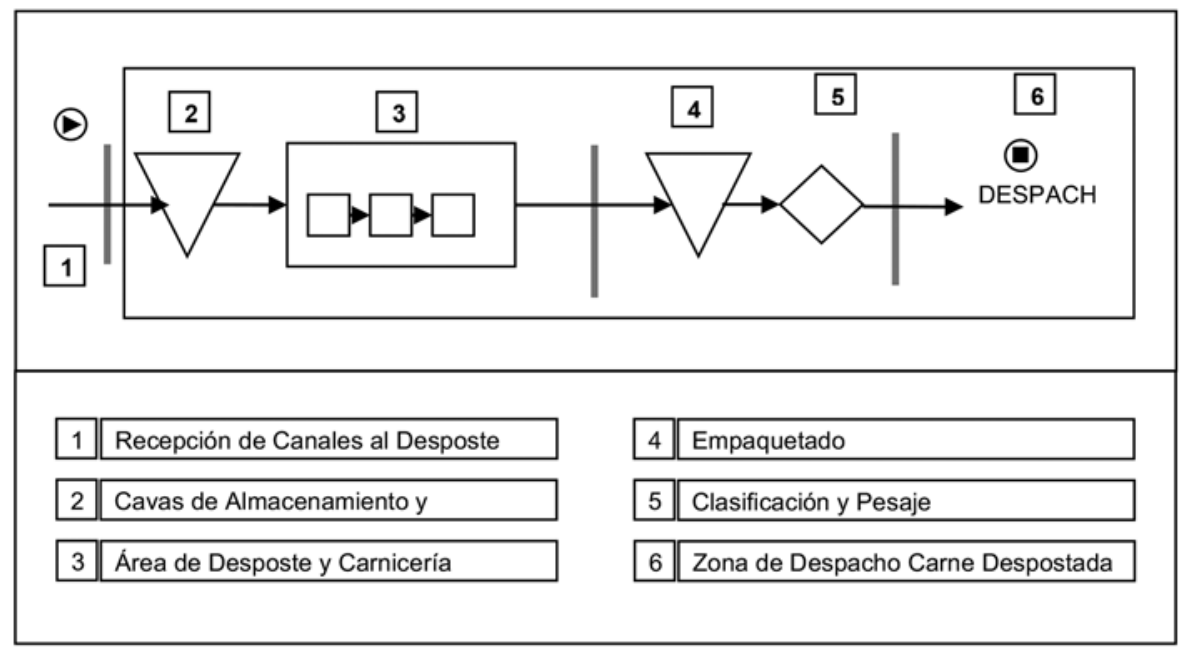

Fuente: Elaboración propia. 
Etapa III. Empaquetado: Con la tecnología de punta, las piezas o cortes de carne se empacan al vacío en una bolsa termodinámica. Posteriormente, las diferentes piezas son identificadas y pesadas.

Etapa IV. Almacenamiento: Los productos finales del desposte para su conservación también se almacenan en las cavas, con los niveles de temperatura y enfriamiento adecuados.

Los procesos productivos de matanza y desposte reúnen las cualidades de los procesos en serie y masificados, caracterizados por una demanda estable de productos, volúmenes de producción elevados y de capital intensivo por requerir maquinaria y equipamiento muy especializados. De estos procesos se obtienen simultáneamente diversos productos de los que, con independencia de que surjan costos separables o no, siempre es posible conocer sus precios de venta en el punto de separación. Lo que significa que se pueden identificar al menos dos puntos de separación: uno, al finalizar el proceso de matanza $y$, el otro, al finalizar el proceso de desposte.

Por otra parte, se evidenció la inexistencia formal de criterios para la acumulación de costos en este tipo de industrias. Normalmente los procesos productivos han registrado una continuidad en su aplicación, sin la búsqueda real de herramientas que permitan obtener información para mantener indicadores de producción, que la gerencia pueda utilizar para planificar acciones estratégicas en pro de mejorar sus niveles de producción. Los sistemas contables se han enfocado a unos registros fundamentados en una contabilidad comercial de registros de ingresos y gastos, sin la aplicación de técnicas fundamentadas en la contabilidad de costos.

En función de las características de producción del sector agroindustrial frigorífico se puede considerar que el sistema de acumulación de costos por procesos, con la aplicación del método de asignación de costos conjuntos basado en el precio de venta de mercado en el punto de separación, son los procedimientos apropiados para la valoración de su producción conjunta. Los lineamientos generales que deberían orientar la formulación de un sistema de acumulación de costos pertinente para las empre- sas de este sector incluyen: plan de informes de las líneas de producción, ampliación del plan de cuentas, estructura de costos y valoración de inventarios.

Un plan de informes de las líneas de producción, que permiten supervisar y controlar todo la información relacionada con el proceso productivo. Por una parte, el informe del proceso de matanza (Tabla 1 ), recoge la información relativa al mes de producción, el peso obtenido por cada tipo de producto y el porcentaje de participación de cada producto; por la otra, el informe general del proceso de desposte (Tabla 2), resume el peso obtenido por cada tipo de producto, el número de lote y reses despostadas y establece el porcentaje de participación de los cortes por cantidad de reses despostadas. Estos porcentajes permiten crear estándares para medir el rendimiento de las reses beneficiadas y controlar el proceso, permitiendo normalizar y controlar la producción.

Tabla 1. Informe general de producción matanza

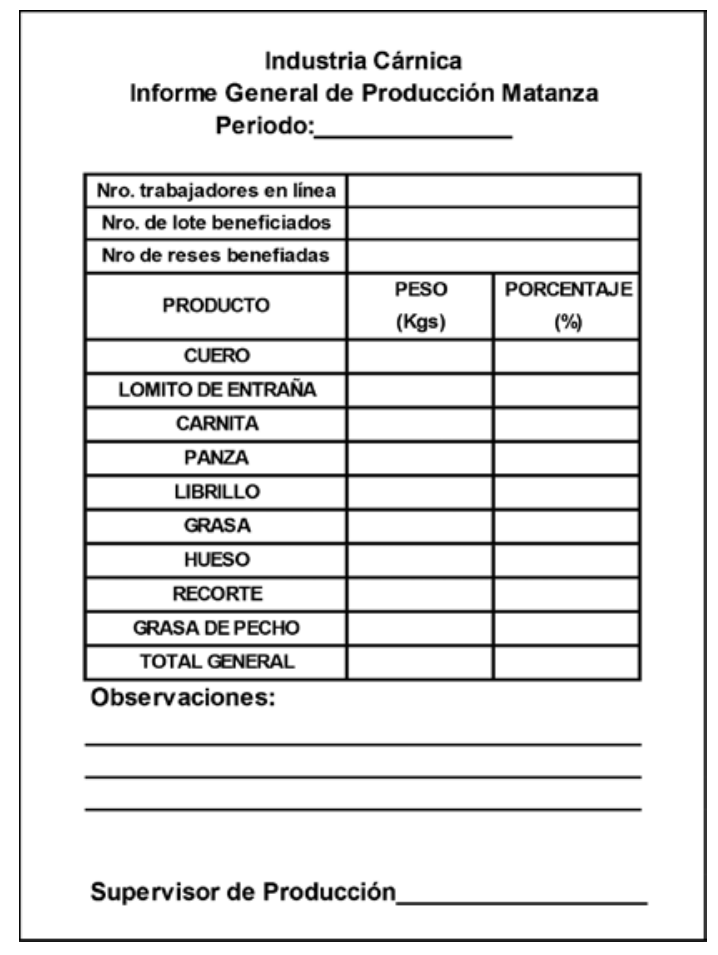

Fuente: Elaboración propia. 
Tabla 2. Informe general de producción desposte

\begin{tabular}{|c|c|c|}
\hline \multicolumn{3}{|c|}{$\begin{array}{l}\text { Industria Cárnica } \\
\text { Informe General de Producción Desposte } \\
\text { Periodo: }\end{array}$} \\
\hline \multicolumn{3}{|c|}{ Nro. trabajadores en línea } \\
\hline \multicolumn{3}{|c|}{ Nro. de lote despostado } \\
\hline \multicolumn{3}{|c|}{ Nro de reses despostadas } \\
\hline PRODUCTO & $\begin{array}{l}\text { PESO } \\
\text { (Kgs) }\end{array}$ & $\begin{array}{c}\text { PORCENTANE } \\
\%\end{array}$ \\
\hline \multicolumn{3}{|l|}{$\begin{array}{l}\text { CORTES DE PRIMERA } \\
\text { EMPACADA AL VACIO }\end{array}$} \\
\hline \multicolumn{3}{|c|}{$\begin{array}{l}\text { CORTES DE SEGUNDA AL } \\
\text { VACIO }\end{array}$} \\
\hline \multicolumn{3}{|l|}{$\begin{array}{l}\text { CORTES DE TERCERA AL } \\
\text { VACIO }\end{array}$} \\
\hline \multicolumn{3}{|l|}{ TOTAL CARNE } \\
\hline \multicolumn{3}{|l|}{ GRASA } \\
\hline \multicolumn{3}{|l|}{ HUESO } \\
\hline \multicolumn{3}{|l|}{ RECORTE } \\
\hline \multicolumn{3}{|l|}{ GRASA DE PECHO } \\
\hline \multicolumn{3}{|l|}{ TOTAL GENERAL } \\
\hline \multicolumn{3}{|l|}{ Observaciones: } \\
\hline \multicolumn{3}{|c|}{ Supervisor de Producción_ } \\
\hline
\end{tabular}

Fuente: Elaboración propia.

El plan de cuentas para el adecuado control y registro de las operaciones requiere incorporar en la contabilidad general o financiera de los frigoríficos industriales, al menos, las siguientes cuentas control correspondientes a cada una de las líneas de producción: Inventario de Carne en Canal, Inventario de Subproductos e Inventario de Carne Despostada. Las cuentas control con sus respectivas codificaciones y auxiliares se presentan en la Tabla 3.

La estructura de costos, esto es, la agrupación de los elementos del costo para el sector agroindustrial frigorífico del estado Mérida, podría realizarse en fichas de costos por procesos. La materia prima se excluye de la estructura de costos del proceso de matanza por cuanto esta área productiva se concibe como una unidad de servicio, por tanto, sólo contempla los costos de mano de obra directa, los otros costos indirectos de producción y la recuperación de costos, que es la cuenta puente que se utiliza para trasladar los costos a las cuentas de inventarios de carne en canal y subproductos, dado que no existe la posibilidad de tener productos en proceso y se hace necesario mantener actualizados los costos de las existencias aprovechando así las ventajas de los registros de inventario continuo (Tabla 4). En el proceso de desposte, la materia prima proviene de las trasferencias que realizan los almacenes de carne en canal, adicionándoles, los costos de mano de obra directa y costos indirectos de fabricación (Tabla 5).

Es importante resaltar que los frigoríficos y mataderos industriales manejan una amplia variedad de costos indirectos de fabricación, siendo los principales los suministros de fábrica y la mano de obra indirecta. Los suministros de fábrica en su mayoría se utilizan para la generación de energía y frío o para el tratamiento químico de insumos operativos $y$, entre ellos, figuran: los combustibles para la generación de vapor de consumo directo, la producción de energía eléctrica o el accionamiento de maquinarias de refrigeración; el amoníaco, la sal y otros productos químicos; algunos empaques menores utilizados en producción; y los lubricantes para las maquinarias.

Estos suministros suelen llamarse materiales operativos, pues aunque no forman parte del producto final son inherentes y necesarios para el normal desenvolvimiento de las operaciones de beneficio y desposte. La mano de obra indirecta incluye principalmente a los aseadores, personal de mecánica y electricidad que laboran en producción, normalmente hacen trabajos de mantenimiento y conservación de la planta, cuyo costo viene representado por el salario.

Asimismo, los desembolsos asociados a la dotación que requiere el personal de la planta -tanto directo como indirecto- tales como botas, cascos, guantes, lentes, bragas, delantales, también son considerados y clasificados como costos indirectos de fabricación. Cada dotación depende de las necesidades de los puestos de trabajo. 
Tabla 3. Plan de cuentas

\begin{tabular}{|c|c|c|c|c|c|}
\hline \multicolumn{2}{|c|}{ INVENTARIO DE CARNE EN CANAL } & \multicolumn{2}{|c|}{ INVENTARIO DE SUBPRODUCTOS } & \multicolumn{2}{|c|}{ INVENTARIO CARNE DESPOSTADA } \\
\hline \multicolumn{2}{|l|}{ Área: Matanza. } & \multicolumn{2}{|l|}{ Área: Matanza. } & \multicolumn{2}{|l|}{ Área: Desposte. } \\
\hline \multicolumn{2}{|c|}{ Tipo de cuenta: Activo Circulante. } & \multicolumn{2}{|c|}{ Tipo de cuenta: Activo Circulante. } & \multicolumn{2}{|c|}{ Tipo de cuenta: Activo Circulante. } \\
\hline \multicolumn{2}{|c|}{$\begin{array}{l}\text { Grupo de activo circulante: Realizable / Inven- } \\
\text { tarios. }\end{array}$} & \multicolumn{2}{|c|}{$\begin{array}{l}\text { Grupo de activo circulante: Realizable / Inventa- } \\
\text { rios. }\end{array}$} & \multicolumn{2}{|c|}{$\begin{array}{l}\text { Grupo de activo circulante: Realizable / Inven- } \\
\text { tarios. }\end{array}$} \\
\hline \multicolumn{2}{|c|}{ Naturaleza de la Cuenta: Real - Deudora. } & \multicolumn{2}{|c|}{ Naturaleza de la Cuenta: Real - Deudora. } & \multicolumn{2}{|c|}{ Naturaleza de la Cuenta: Real - Deudora. } \\
\hline \multicolumn{2}{|c|}{$\begin{array}{l}\text { Descripción: Existencia de carne en canal, dis- } \\
\text { ponibles para la venta y para ser enviadas al } \\
\text { proceso de desposte. }\end{array}$} & \multicolumn{2}{|c|}{$\begin{array}{l}\text { Descripción: Existencia de subproductos, dis- } \\
\text { ponibles para la venta y/o para ser enviadas al } \\
\text { proceso de desposte. }\end{array}$} & \multicolumn{2}{|c|}{$\begin{array}{l}\text { Descripción: Existencia de carne despostada, } \\
\text { disponibles para la venta. }\end{array}$} \\
\hline \multicolumn{2}{|c|}{ Se debita: Cuando se compra carne en canal. } & \multicolumn{2}{|c|}{$\begin{array}{l}\text { Se debita: Cuando se conoce el resultado de pro- } \\
\text { ductos obtenidos en el proceso de matanza. }\end{array}$} & \multicolumn{2}{|c|}{$\begin{array}{l}\text { Se debita: Cuando se conoce el resultado de } \\
\text { productos obtenidos en el proceso de desposte. }\end{array}$} \\
\hline \multicolumn{2}{|c|}{$\begin{array}{l}\text { Se acredita: Cuando se efectúan ventas de car- } \\
\text { ne en canal y/o cuando se realizan transferen- } \\
\text { cias de este producto al proceso de desposte. }\end{array}$} & \multicolumn{2}{|c|}{$\begin{array}{l}\text { Se acredita: Cuando se efectúan ventas de sub- } \\
\text { productos y/o cuando se realizan transferencias } \\
\text { de este producto al proceso de desposte }\end{array}$} & \multicolumn{2}{|c|}{$\begin{array}{l}\text { Se acredita: Cuando se efectúan ventas de car- } \\
\text { ne despostada. }\end{array}$} \\
\hline \multicolumn{2}{|l|}{ Cuentas Auxiliares: } & \multicolumn{2}{|l|}{ Cuentas Auxiliares: } & \multicolumn{2}{|l|}{ Cuentas Auxiliares: } \\
\hline Código Contable & Descripción & Código Contable & Descripción & Código Contable & Descripción \\
\hline T11101- & AA & T11100- & CRIADILLA & T21101- & LOMITO \\
\hline T11102- & AM & T11100- & PIÑA COMPLETA & T21101- & SOLOMO DE CUERITO \\
\hline T11103- & $\mathrm{AH}$ & T11100- & RIÑON & T21101- & GANSO \\
\hline T11104- & B & T11100- & LOMITO ENTRAÑA & T21101- & PUNTA TRASERA \\
\hline T11105- & C & T11100- & BILIS & T21101- & PULPA NEGRA \\
\hline \multirow[t]{11}{*}{ T11106- } & \multirow[t]{11}{*}{$\mathrm{D}$} & T11100- & PENES & T21101- & CHOCOZUELA \\
\hline & & T11100- & RABOS & T21101- & MUCHACHO REDONDO \\
\hline & & T11100- & MEDULA & \multirow{2}{*}{ T21101- } & \multirow{2}{*}{$\begin{array}{l}\text { MUCHACHO CUA- } \\
\text { DRADO }\end{array}$} \\
\hline & & T11100- & PIEL DE COLA & & \\
\hline & & \multirow[t]{7}{*}{ T12000- } & \multirow[t]{7}{*}{ LENGUA } & T21102- & SOLOMO ABIERTO \\
\hline & & & & T21102- & PALETA \\
\hline & & & & T21102- & PAPELON \\
\hline & & & & T21102- & LAGARTO LA REINA \\
\hline & & & & T21102- & FALDA \\
\hline & & & & T21102- & SOBREBARRIGA \\
\hline & & & & T21203- & COSTILLA \\
\hline
\end{tabular}

Fuente: Elaboración propia. 
Tabla 4. Estructura de costos - matanza

\begin{tabular}{|c|c|c|}
\hline ELEMENTOS DEL COSTO & PARTIDAS CONTABLES & COSTO (BS.) \\
\hline \multirow{10}{*}{$\begin{array}{l}\text { MANO DE } \\
\text { OBRA DIRECTA }\end{array}$} & Salarios & \\
\hline & Horas extras & \\
\hline & Prestaciones Sociales & \\
\hline & Intereses S/ Prestaciones & \\
\hline & Utilidades & \\
\hline & Vacaciones & \\
\hline & Bono de Alimentación & \\
\hline & Gastos Médicos & \\
\hline & Dotaciones & \\
\hline & Prima de Seguro & \\
\hline \multirow{6}{*}{$\begin{array}{l}\text { COSTOS } \\
\text { INDIRECTOS }\end{array}$} & Mano de Obra Indirecta & \\
\hline & Depreciación Equipo de Producción & \\
\hline & Electricidad & \\
\hline & Mantenimiento Planta & \\
\hline & Productos Químicos & \\
\hline & Combustible y Lubricantes & \\
\hline CUENTA PUENTE & RECUPERACIÓN DE COSTOS & \\
\hline
\end{tabular}

Fuente: Elaboración propia.

Para la valoración de inventarios, dado que los proceso de matanza y desposte generan simultáneamente múltiples productos, los costos conjuntos deben repartirse entre los diversos productos utilizando alguno de los métodos de asignación de costos conjuntos. Los productos cárnicos son variables en cuanto a las cantidades producidas y sus respectivos precios de mercado, por eso el más conveniente para costearlos es el método de los valores de ventas en el punto de separación. En efecto, este procedimiento es preferible cuando existen datos del precio de venta en el punto de separación, incluso si se incurre en costos separables por un procesamiento adicional (Horngren et al., 2012).
El método de los valores de ventas en el punto de separación supone que todos los productos finales deben rendir algún margen de utilidad, por tanto, aplica los costos conjuntos en proporción a la capacidad de cada producto para absorber dichos costos a través de los ingresos por ventas que contribuyen a redituar, cubriendo con ellos los costos totales más un rendimiento razonable. La definición y asignación de costos conjuntos siguen los mismos lineamientos para ambos procesos, no obstante, en la Tabla 6 solo se muestra la valoración de los productos finales del proceso de desposte para ilustrar el procedimiento. 
Tabla 5. Estructura de costos - desposte

\begin{tabular}{|c|c|c|}
\hline ELEMENTOS DEL COSTO & PARTIDAS CONTABLES & COSTO (BS.) \\
\hline \multirow{5}{*}{$\begin{array}{l}\text { MATERIA } \\
\text { PRIMA }\end{array}$} & Canales AA-M & \\
\hline & Canales A-M & \\
\hline & Canales A-H & \\
\hline & Canales C-M & \\
\hline & Canales D-M & \\
\hline \multirow{9}{*}{$\begin{array}{l}\text { MANO DE OBRA } \\
\text { DIRECTA }\end{array}$} & Salarios & \\
\hline & Horas extras & \\
\hline & Prestaciones Sociales & \\
\hline & Intereses S/ Prestaciones & \\
\hline & Utilidades & \\
\hline & Vacaciones & \\
\hline & Bono de Alimentación & \\
\hline & Gastos Médicos & \\
\hline & Dotaciones & \\
\hline \multirow{7}{*}{$\begin{array}{l}\text { COSTOS } \\
\text { INDIRECTOS }\end{array}$} & Mano de Obra Indirecta & \\
\hline & Prima de Seguro & \\
\hline & Material de Empaque & \\
\hline & Depreciación Equipo de Producción & \\
\hline & Electricidad & \\
\hline & Mantenimiento Planta & \\
\hline & Combustible y Lubricantes & \\
\hline CUENTA PUENTE & RECUPERACIÓN DE COSTOS & \\
\hline
\end{tabular}

Fuente: Elaboración propia.

Los costos de la materia prima para despostar lo constituye el costo de compra d§e la carne en canal, el cual representa la mayor erogación económica, adicionando costo por mano de obra directa y costos indirectos de fabricación, estos últimos incluyen costos de refrigeración y manejo en los almacenes de la carne en canal. Para calcular los costos unitarios de producción de la carne despostada es necesario determinar los precios referenciales de venta para cada tipo de producto conjunto y subproducto. Este procedimiento cuando se trata de estructuras para formulación de precios de venta, debe considerar los porcentajes de rentabilidad deseados, $e$ igualmente las posibles fluctuaciones y/o regulaciones que se puedan ocasionar en los mercados nacionales. Posteriormente, se asignan los costos conjuntos a cada producto considerando la participación en función a las ventas totales, de esta manera el modelo asigna mayor costo al producto que presenta el precio referencial más alto. Por último, se divide el costo conjunto entre las unidades producidas para determinar el costo unitario para cada corte de carne y subproducto obtenido. En los libros contables el traspaso de los costos conjuntos hacia las cuentas de inventario se registra utilizando la cuenta recuperación de costos (Tabla 7). 
Tabla 6. Determinación de costos unitarios carne despostada

\begin{tabular}{|c|c|c|c|c|c|}
\hline \multicolumn{6}{|c|}{$\begin{array}{c}\text { DETERMINACIÓN COSTOS UNITARIOS DE PRODUCCIÓN } \\
\text { CARNE DESPOSTADA } \\
\text { PERIODO }\end{array}$} \\
\hline \multirow{3}{*}{$\begin{array}{l}\text { CARNE DESPOSTADA } \\
\text { PERIODO }\end{array}$} & \multicolumn{2}{|r|}{$\begin{array}{r}\text { COSTO TOTAL CONJUNTO } \\
\text { DESPOSTE }\end{array}$} & \multicolumn{2}{|l|}{$1.500 .914,00$} & \\
\hline & \multicolumn{2}{|r|}{ TOTAL KG. DESPOSTADOS } & \multicolumn{2}{|l|}{$287.428,55$} & \\
\hline & \multicolumn{2}{|r|}{$\begin{array}{r}\text { COSTO TOTAL DESPOSTE } \\
(\mathrm{Bs} / \mathrm{Kg})\end{array}$} & \multicolumn{2}{|l|}{5,22} & \\
\hline \multirow[t]{2}{*}{ CORTES } & $\begin{array}{l}\text { PRECIO DE } \\
\text { REFERENCIA }\end{array}$ & $\begin{array}{l}\text { PRODUCCIÓN } \\
\text { KGS }\end{array}$ & $\begin{array}{c}\text { VENTAS } \\
\text { PRODUCCIÓN }\end{array}$ & $\begin{array}{l}\text { COSTO CONJUNTO } \\
\text { ASIGNADO }\end{array}$ & $\begin{array}{l}\text { COSTO } \\
\text { UNITARIO }\end{array}$ \\
\hline & (A) & (B) & $C=(A \times B)$ & $E=\left(\begin{array}{ll}\% & C\end{array}\right)$ & $F=(E / A)$ \\
\hline LOMITO & 25,00 & $4.597,60$ & $114.940,00$ & $59.096,31$ & 12,85 \\
\hline CORTES DE PRIMERA & 17,00 & $74.569,96$ & $1.267 .689,32$ & $651.781,43$ & 8,74 \\
\hline CORTES DE SEGUNDA & 15,00 & $73.521,89$ & $1.102 .828,35$ & $567.018,30$ & 7,71 \\
\hline LAGARTO CON HUESO & 12,00 & $6.724,20$ & $80.690,40$ & $41.486,90$ & 6,17 \\
\hline COSTILLA & 13,00 & $20.726,10$ & $269.439,30$ & $138.532,00$ & 6,68 \\
\hline RECORTE & 5,00 & $6.663,80$ & $33.319,00$ & $17.130,94$ & 2,57 \\
\hline HUESO & 0,50 & $65.207,00$ & $32.603,50$ & $16.763,06$ & 0,26 \\
\hline GRASA & 0,50 & $35.418,00$ & $17.709,00$ & $9.105,07$ & 0,26 \\
\hline TOTAL & & $287.428,55$ & 2.919.218,87 & $1.500 .914,00$ & \\
\hline
\end{tabular}

Fuente: Elaboración propia.

Tabla 7. Registro contable de los costos del desposte

\begin{tabular}{|c|l|r|r|}
\hline \multicolumn{5}{|c|}{$\begin{array}{c}\text { DEPARTAMENTO DE CONTABILIDAD } \\
\text { LIBROS CONTABLES } \\
\text { (Expresados en Bs) }\end{array}$} \\
\hline CÓDIG0 CONTABLE & \multicolumn{1}{|c|}{ DESCRIPCIÓN } & \multicolumn{1}{c|}{ DEBE } & HABER \\
\hline T21101- & LOMITO & $59.096,31$ & \\
\hline T21101- & CORTES DE PRIMERA & $651.781,43$ & \\
\hline T21101- & CORTES DE SEGUNDA & $567.018,30$ & \\
\hline T21101- & LAGARTO CON HUESO & $41.486,90$ & \\
\hline T21101- & COSTILLA & $138.532,00$ & \\
\hline T21101- & RECORTE & $17.130,94$ & \\
\hline T21101- & HUESO & $16.763,06$ & \\
\hline T21101- & GRASA & $9.105,07$ & \\
\hline T9999- & RECUPERACIÓN DE COSTOS & $1.500 .914,00$ \\
\hline
\end{tabular}

Fuente: Elaboración propia. 


\section{Conclusiones}

La evolución de las operaciones de fabricación del sector agroindustrial frigorífico ha hecho que los esquemas gerenciales respondan dinámicamente con estructuras, métodos y procedimientos a los cambios presentes. Los costos, como instrumentos de ejecución financiera, se han convertido en elementos indispensables de la administración. La preparación de información financiera así como el adecuado desarrollo de las funciones de planeación, control y toma de decisiones necesariamente requiere del costeo de bienes y/o servicios.

Esto adquiere aún más importancia en Venezuela, que se caracteriza por ser un escenario que pretende controlar los precios y márgenes de rentabilidad de todas las actividades económicas y, en particular, de la producción cárnica. Los diversos decretos presidenciales en la materia y la Ley Orgánica de Precios Justos (LOPJ) son los mecanismos jurídicos utilizados para fijar los determinados niveles de precios en ciertos rubros estratégicos (alimentos, medicinas, repuestos, etc.) y exigir las estructuras de costos de los productos que ofertan las empresas.

Por estos motivos, las empresas del sector agroindustrial frigorífico deberían contar con un sistema de acumulación de costos que sea compatible con la naturaleza de su proceso productivo y que les posibilite el cálculo del costo unitario, la valoración de inventarios y la determinación de la utilidad. El sistema de acumulación de costos por procesos es el que mejor se ajusta al proceso de beneficio de reses para el consumo masivo. Este sistema le permitirá a la gerencia el control adecuado de los costos de producción, a través de los informes departamentales, con miras a la toma de decisiones relacionadas con políticas de precios, optimización de los costos y participación activa en las mesas de negociaciones con los entes reguladores.

Pero para efectos de costeo y elaboración de las estructuras de costos de los productos conjuntos y subproductos que obtienen, deben valerse de métodos de asignación de costos conjuntos. El método más conveniente sería el de los valores de ventas en el punto de separación, aunque autores como Hor- ngren et al. (2012), recomienden que en contextos con regulaciones de precios el método de unidades físicas es el de mayor utilidad para evitar el razonamiento circular derivado del uso simultáneo de los precios de venta como base para la fijación de precios y aplicación de los costos sobre los cuales se fundamentan esos precios. Contrariamente, fuera de este razonamiento, los productos regulados o no deben generar suficientes ingresos para cubrir todos los costos más un rendimiento razonable que permita el funcionamiento de las empresas en el tiempo, por tanto, también se le debe prestar atención a su capacidad para absorber costos conjuntos.

No hay que olvidar que las distribuciones de costos conjuntos son arbitrarias y, en última instancia, dependen de las decisiones gerenciales y las condiciones del entorno económico en el que operan las empresas. Incluso tampoco, como Overland \& Sandoff (2014) confirman, que la elección del método de asignación tiene un impacto sustancial en la rentabilidad informada de los diversos segmentos de negocios. Por consiguiente, la selección de un método de asignación de costos conjuntos debe considerar múltiples aspectos del contexto empresarial, tales como el propósito del costeo, la intensidad de la competencia del sector industrial o el tipo de sistema económico dominante, ya sea, que se trate de una economía de mercado, planificada o mixta.

Con todo, hay que destacar que acudir a los precios de mercado para la asignación de los costos conjuntos es una práctica que está refrendada (Cañibaño \& Mallo, 1974). Cats-Baril et al. (1986) sugieren que el método de los valores de ventas en el punto de separación resulta mejor que el método de las unidades físicas para la distribución de los costos conjuntos, si se puede cambiar la mezcla física de la producción incurriendo en más o en menos costos conjuntos y, con ello, se produce un mayor o un menor valor de mercado. En tanto que Gatti \& Grinnell (2000), evidencian que las asignaciones de costos conjuntos en base a los valores de mercado son superiores para promocionar la productividad y el mejoramiento de la calidad.

Las implicaciones de la utilización del método de los valores de ventas en el punto de separación para los 
mataderos y frigoríficos industriales, pueden ir más allá del mero costeo de productos. Dado que este método prorratea los costos conjuntos con base en la participación proporcional de cada producto en el valor de mercado, entre más alto sea el valor de referencia de venta en el punto de separación, mayor será la porción del costo conjunto cargada a ese producto y viceversa, lo que les posibilitaría acoplarse al comportamiento de los precios regulados y referenciales de los mercados activos de productos cárnicos. Igualmente, se beneficiarían de un método sencillo y fácil de poner en práctica que de hacerse extensivo podría generar datos comparables dentro de la industria para la formación de precios, que aseguren que los productos conjuntos reditúen el ingreso combinado suficiente a largo plazo que cubran los costos conjuntos, así como, que los productos no regulados no subsidien a los productos regulados.

El reto de los profesionales en el área de costos, entonces, será implantar más y mejores herramientas que reporten información para el correcto costeo de los productos y la toma de decisiones en todos los tipos de negocios. En la medida que la globalización y la competencia crecen, aumenta también la necesidad de adaptación de los sistemas de información contable a las nuevas condiciones del entorno productivo y reglas de juego que rigen las transacciones económicas.

\section{Referencias}

Asofrigo (2010). Informe de Gestión 2006 y 2007. [Página web en línea]. Disponible en URL: http://www.analitica.com.

Backer, M., Jacobsen, L. \& Ramírez, D. (1983). Contabilidad de Costos: Un Enfoque para la Toma de Decisiones (2da. ed.). Naucalpan de Juárez, México: Mc Graw-Hill Interamericana.

Balestrini, M. (2002). Como se Elabora el Proyecto de Investigación. Caracas, Venezuela: Consultores Asociados, Servicio Editorial.

Cañibaño, L. \& Mallo, C. (1974). El Cálculo de los Costes en la Producción Conjunta. Revista Española de Financiación y Contabilidad, III (8), 305-336.

Cats-Baril, W., Gatti, J. \& Grinnell, D. (1986). Joint Product Costing in the Semiconductor Industry. Management Accounting, 67 (8), 28-31, 34-35.

Chacón, G. (2007). La Contabilidad de Costos, los Sistemas de Control de Gestión y la Rentabilidad Empresarial. Actualidad Contable FACES, 10 (15), 29-45.
Chacón, G. (2010): Práctica de la Contabilidad de Costos y la Rentabilidad de las Pymes del Municipio Libertador del Estado Mérida. Tesis de Maestría no publicada. Universidad de Los Andes, Mérida, Venezuela.

García, J. (2001). Contabilidad de Costos (2da ed.). México Distrito Federal, México: Mc. Graw Hill Interamericana.

Gatti, J. \& Grinnell, D. (2000). Joint Cost Allocations: Measuring and Promoting Productivity and Quality Improvements. Journal of Cost Management, 4 (4), 13-21.

Gayle, L. (1999). Contabilidad y Administración de Costos (6ta. ed.). México Distrito Federal, México: Mc Graw-Hill Interamericana.

Gómez, B. (2005). Contabilidad de Costos (5ta ed.). Santa Fe de Bogotá, Colombia: Mc. Graw Hill Interamericana.

Hansen, D. \& Mowen, M. (2007). Administración de Costos: Contabilidad y Control (5ta. ed.). México Distrito Federal, México: Cengage Learning Editores.

Hargadon, B., \& Múnera, A. (2004). Contabilidad de Costos. Bogotá, Colombia: Editorial Norma.

Horngren, Ch., Datar, S. \& Rajan M. (2012). Contabilidad de Costos: Un Enfoque Gerencial (14ta. ed.). Naucalpan de Juárez, México: Pearson Educación.

Lang, T. (1981). Manual del Contador de Costos. México Distrito Federal, México: Editorial Limusa.

Lavolpe, A. (2005): Los Sistemas de Costos y la Contabilidad de Gestión: Pasado, Presente y Futuro. Costos y Gestión, (5), 661-672.

López, M. (1999): "El Cambio y la Cultura Organizacional al Diseñar un Sistema de Información de Gestión y su Reflejo en un Cuadro de Manera Integral". Gestión y Estrategia, (15), pp. 103-114

Meigs, R. \& Meigs, W. (1994). Contabilidad: La Base para Decisiones Gerenciales (11va. ed.). Bogotá, Colombia: Mc Graw-Hill Interamericana.

Morillo, M. (2002). Diseño de Sistemas de Costeo: Fundamentos Teóricos. Actualidad Contable FACES. 5 (5), 7-22.

Neuner, J. \& Deakin, E. (1982). Contabilidad de Costos: Principios y Prácticas. México Distrito Federal, México: Editorial Limusa.

Oropeza, H. (2005). Los Costos en la Empresa: Guía Técnica. México Distrito Federal, México: Editorial Trillas.

Ortega, A. (1997). Contabilidad de Costos. Instituto Mexicano de Contadores Públicos, México Distrito Federal, México: Editorial Limusa.

Overland, C. \& Sandoff, A. (2014). Joint Cost Allocation and Cogeneration [Working paper en línea]. Consultado el 03 de Marzo de 2016. Disponible en URL: http://gup.ub.gu.se/ records/fulltext/194779/194779.pdf

Piñate, P. (2010). Atrasado el Mercado Cárnico en Venezuela. Notas Agropecuarias Venezuela [Blog en línea]. Consultado el 15 de Septiembre de 2014. Disponible en URL: https:// agronotas.wordpress.com/2010/05/11/carne-24/

Polimeni, R., Fabozzi, F., Adelbeg, A. \& Kole, M. (1994). Contabilidad de Costos: Conceptos y Aplicaciones para la Toma de Decisiones Gerenciales (3ra. ed.). Santa Fe de Bogotá, Colombia: Mc Graw-Hill Interamericana.

Sabata, A. (2010). Propuesta Metodológica para la Valoración de la Producción en Empresas Ganaderas. Una Aplicación Práctica al Sector Ganadero Porcino. Revista Iberoamericana de Contabilidad de Gestión [Revista en línea], VIII (15). Consultado el 03 de Marzo de 2016. Disponible en URL: http:// 
www.observatorio-iberoamericano.org/RICG/N\%C2\%BA_15/ Anna_Sabata_Aliberch.pdf

Segovia, E. \& Jerez, N. (2008): Nudos Críticos en la Cadena Cárnica Bovina. En Gonzáles, C., Madrid, M. y Soto E. (Eds.), Desarrollo Sostenible de la Ganadería Doble Propósito (pp. 805-817). Maracaibo, Venezuela: Fundación Girarz, Ediciones Astro Data.
Sierra, R. (2002, Abril 22). Columna Semanal. El mundo de las Organizaciones. Diario Frontera, p. C-2.

Sinisterra, G. (2006). Contabilidad de Costos. Bogotá, Colombia: Ediciones Ecoe.

Torres, A. (2002). Contabilidad de Costos: Análisis para la Toma de Decisiones (2da. ed.). México Distrito Federal, México: Mc Graw-Hill Interamericana. 